\title{
Assessing long term performance of magnesia-based binders in contaminated land remediation
}

\author{
Fei Jin ${ }^{1}$ \\ ${ }^{1}$ School of Engineering, Cardiff University, \\ Wales, UK CF24 3AA \\ * Corresponding author. E-mail: jinf2@ cardiff.ac.uk
}

Binders have been widely used in land remediation projects including soil stabilisation/solidification, low permeability cutoff walls and soft soil improvement. Portland cement (PC) is the most prevalent binder used conventionally though concerns regarding its negative environmental impact and long-term durability have been raised more often in recent years. Consequently there are strong incentives for the development of green and durable binders for use in land remediation projects to ensure a safer and more sustainable solution. Magnesia $(\mathrm{MgO})$ could be produced from calcination of magnesite or dolomite rocks and from a wide range of magnesiumcontaining wastes such as desalination brines. There is also abundant $\mathrm{Mg}$ source in the seawater and magnesium silicate rocks. The unique feature of reactive grade $\mathrm{MgO}$ to react readily with water, $\mathrm{CO}_{2}$ and other aluminosilicate materials to generate various products with excellent adsorptive and metal immobilisation performance has made it a potentially greener and high-performance binder in land remediation projects. This talk will give a brief overview on the production and characteristics of reactive $\mathrm{MgO}$ followed by an introduction of a suite of $\mathrm{MgO}-$ based binders. The laboratory investigation on the use of $\mathrm{MgO}$-based binders in heavy metal contaminated soil remediation and low permeability cutoff walls are presented, which demonstrates their excellent long-term mechanical and hydraulic properties and heavy metal immobilisation capacity. Moreover, the three-year field performance of these $\mathrm{MgO}$-based binders in contaminated soil stabilisation has clearly showed their superior longterm durability than PC under the field conditions. These results could be used in the development of full-scale land remediation strategy with $\mathrm{MgO}$-based binders to achieve better long-term performance and potentially lower carbon footprint.

Keywords: reactive magnesia, long-term durability, field trial, soil stabilisation/solidification, low permeability cutoff wall 